\title{
Capacity building to reduce maternal and neonatal morbidity and mortality
}

\author{
By T Lavender, H Lugina, P Vidot, A Chimwaza, C Bedwell, P Donovan, T Kohi, P Dlammani, E Tsekiri \\ and M Msuya
}

$\mathbf{T}$ The fifth Millennium Development Goal (MDG) calls for improving maternal health (United Nations General Assembly, 2000). However, trends suggest that sub-Saharan Africa (the region with the highest level of maternity mortality), is making little progress (United Nations General Assembly, 2005). Sub-Saharan Africa has only 4\% of health workers but $25 \%$ of the global burden of disease (World Health Organization (WHO), 2006). Strategies to assist with these targets are imperative and midwives, as frontline carers, are pivotal to any strategic success.

Of the 57 countries in the world with critical shortages of health professionals, 36 are in sub-Saharan Africa (WHO, 2006). To reduce this deficit, the WHO suggested a strategy that builds strong training institutions, strengthens professional regulation and revitalizes recruitment. In its two key resolutions it called for 'country leadership' and 'global solidarity'. Essential to both resolutions is the focus on knowledge, learning and education. The need for evidence-based guidelines and appropriate research are also recommended. However, currently there are very few midwives trained to masters level in the East Central and South Africa (ECSA) region. Those who have achieved this level of training have done so via the developed world. In sub-Saharan Africa, there are no opportunities for even the midwifery tutors to be trained to this level, a fact that is increasingly unacceptable.

Within the ECSA region the midwifery profession remains relatively stagnant. Research is in its infancy resulting in poor availability of data and a deficiency of information to deal with complex health issues. Moreover, the image of midwifery, as a profession, has been somewhat compromised as more attractive professions have created a shortage of recruits. Midwives wishing to develop their professional skills have been forced to migrate to developed countries offering postgraduate courses unavailable in their region. This further compounds the problem of staff shortages. However, the nursing and midwifery profession in the region, comparatively, lags behind the profession in developed countries. Midwifery leaders are needed to drive future strategies and influence future health.

Recruitment and retention of midwives is difficult and incentives are crucial in order to have the right skill mix at the right place to improve performance. However, the experience of countries that have used monetary incentives to address motivation and imbalances in the geographical distribution of health workers indicates that non-monetary incentives are as important (Mathauer and Imhoff, 2006). Factors such as proximity to the family, attending courses, opportunities for research and teaching also influence an individual's decision about where to work (Manongi et al, 2006); factors which can be accommodated through a distance learning course.

\section{Abstract}

In sub-Saharan Africa midwifery educators are in short supply and opportunities to pursue advanced education are severely restricted. Postgraduate programmes that encourage critical thinking and strategic planning in midwifery education, practice, management and research are required to empower midwives to lead their profession.

A unique user-led distance learning programme was developed by adopting a participatory approach to developing a curriculum for a Masters in Midwifery and Women's Health. Midwives from the East Central and South Africa (ECSA) region and the UK participated along with a representative from the Commonwealth Secretariat and International Confederation of Midwives (ICM). The curriculum was based on shared goals but adaptable to cultural and local context. Brainstorming sessions, informal workshops and formal consensus methods were used to reach decisions regarding modules and subsequent content. This article describes the process of developing a shared curriculum, the challenges faced in working across and within regions, and participants' views of contributing to the end product.

Measures are needed to assist midwives to cope with scientific, technological and cultural developments and empower them to lead their profession. This can be achieved through a postgraduate programme that encourages critical thinking and strategic planning in midwifery education, practice, management and research. Such a course must be sensitive to contextual needs and flexible to individuals.

T Lavender is Professor of Midwifery, University of Manchester, UK; H Lugina is Coordinator of the Human Resources Development and Capacity Building Programme of ECSA Health Community Secretariat, Tanzania; P Vidot is Advisor (Health), Social Transformation Programmes Division, Commonwealth Secretariet; A Chimwaza is Dean of Postgraduate Programmes, University of Malawi, Malawi; C Bedwell is Research Midwife, University of Manchester, UK; P Donovan is Principal Lecturer, University of Central Lancashire, UK; T Kohi is Lecurer and Dean of the School of Nursing, Muhimbili University College of Health Science, Tanzania; P Dlammani is Dean of Health Sciences, University of Swaziland; E Tsekiri is Research Assistant, University of Manchester, UK; M Msuya is Dean of the Faculty of Nursing, Kilimanjaro Christian Medical College

Email: Tina.Lavender@manchester.ac.uk 
Aim

The aim of this project was to develop distance learning materials that have the potential to strengthen the capacity of midwives to meet local health needs. It had three main objectives:

- To gain consensus on a shared Masters in Midwifery and Women's Health curriculum

- To validate distance learning materials leading on to a validated course

- To formally assess the views and experiences of project participants.

\section{Method}

\section{Needs assessment}

A needs assessment conducted on two occasions (ECSACON Conference, Sept 2006; South Africa Stakeholder meeting 2007) with heads of higher education institutes identified the motivation for postgraduate education in the field of midwifery and women's health. Midwifery teachers were identified as an important cohort who, through advanced learning, have the ability to positively influence the profession and subsequent practice. The needs analysis found variation in the skills and resources currently available in the ECSA region and differing desires in relation to the mode of delivery of the course. Some universities required distance learning courses, whereas others required face-to-face delivery. Additionally, some institutions wanted part-time courses, while others wanted full-time courses.

\section{Programme development}

A unique user-led distance learning programme was elaborated by adopting a participatory approach to curriculum development. The course aim was to produce critically evaluative practitioners, capable of developing maternity care in their own environment, promoting a humanizing, safe experience for mothers and families. Initially, a steering committee was set up, which met in New Delhi in 2007 to develop a curriculum framework and plan a workshop for wider participation. Subsequently, midwives from 11 ECSA countries (Tanzania, Uganda, Zimbabwe, Seychelles, Mauritius, Kenya, Swaziland, Malawi, Zambia, Namibia and South Africa) participated in a 4-day curriculum planning and module development workshop in Uganda. Brainstorming sessions, informal workshops and formal consensus methods were used to reach decisions regarding modules and subsequent content. Parallel workshops enabled participants to contribute based on their expertise.

\section{Workshop process}

The workshop began with a plenary session, which provided the opportunity for participants to be updated with the rationale and progress for the project. The participants were requested to complete a baseline proforma to ascertain their area and level of expertise. This information was used to assist with assigning participants to workshops. There was a discussion of the workshop objectives and explanation of the process. Participants were given opportunity to discuss the proposed modules and the format of the materials, with exemplars provided. A consensus was reached regarding the core modules and delivery method. Core modules were:

- Research

- Culture

- Education

- Leadership

- Advanced midwifery practice

- Women's health.

The programme scheduled three workshops to run concurrently (workshops 1-3 for 1 day and workshops 4-6 for 2 days) in which participants developed the aims, learning outcomes, course content and assessments for each module. A facilitator was assigned to each workshop and the participants allocated the roles of timekeeper, rapporteur to take records and feedback person to present the module back to the whole group at the following plenary session for discussion and comments.

\section{Workshop evaluation}

Quantitative and qualitative methods of assessing participants' views of workshop attendance were used.

\section{Quantitative}

On the final day of the workshops participants were invited to complete a one-page evaluation sheet of their experience of being a workshop participant. The first part of the evaluation asked participants to indicate, by ticking a box, their level of satisfaction in a number of areas:

- Good clear aims and objectives

- Achievement of aims and objectives

- Quality of sessions

- Ability to participate

- Relevance to own HEI

- Ability to build own capacity

- Help with workshop problems.

Participants were able to choose one of the following responses: 'very good', 'good', 'satisfactory,' 'very poor' or 'poor'.

The latter part of the questionnaire encouraged open responses. Participants were asked to complete two sentences - 'The best aspect of the workshop was ...' and 'The worst aspect of the workshop was ...'. Participants could decide whether or not they wished to include their name on the evaluation sheet

\section{Qualitative}

Qualitative inquiry was led by an independent researcher who conducted face-to-face interviews or telephone interviews with a subgroup of participants. Participants for the qualitative evaluation were identified from those who had taken part in the workshops. Initial evaluation sheets completed following the workshops had requested details of those willing to be interviewed for a more detailed qualitative evaluation. A semi-structured approach was used. The interview schedule was guided by the responses to the evaluation questionnaire.

\section{Findings}

\section{Quantitative}

A total of 29 participants completed the evaluation in which aspects could be rated as either 'very good', 'good', 
'satisfactory', 'poor' or 'very poor'. For all but one of the statements (Figures 1-8) participants stated 'good' or 'very good.' The only criteria that received a negative response was 'satisfaction with room facilities'. One participant said this was 'poor' and 14 stated 'satisfactory.' The remainder stated 'good or 'very good'. Participants were also asked to complete two statements.

'The best aspect of the workshop was...'

The most frequently occurring responses related to:

- Sharing of ideas

- Valuing each other's contribution

- Coming together as a team

Good interaction

- Inclusiveness

- Stimulating content

- Positivity

- Producing a high quality end product

- Good time-keeping

- Mutuality of effort

- Transparency.

This latter point related to ownership of the course materials. It was decided by the participants that the curriculum outline would be shared by all participants, but each institution would adapt the content according to local need and institutional regulations. Additionally, some participants stated that it was a privilege to 'contribute to something that will save lives'.

'The worst aspect of the workshop was...'

Most participants $(n=23)$ stated that there were no negative aspects of the workshops. Those that did record something stated that the hotel facilities were poor. Two members also stated that there were members in their workshop who had materials that would have been useful, but they were unwilling to share them.

\section{Qualitative}

Eight participants who had indicated their willingness to contribute were interviewed in November 2007. Participants from Tanzania, Kenya, Namibia, Zambia and the UK were interviewed. Five participants were interviewed face to face during the Africa Midwives Research Network conference and one by telephone shortly afterwards. Two participants were interviewed face to face in the UK in the two weeks following the conference.

All the individuals approached agreed to participate and consented to interviews being audio-taped. Anonymity was assured for those participating.

\section{Role of participants within workshops}

The participants interviewed covered a range of roles held within workshops. They included facilitators, rapporteurs, those giving feedback to plenary sessions, presenters and session participants. On a personal level, they saw their role as bringing their own and the views of the institution they represented to the sessions. Many also saw their role to take away information from these sessions to feed back to their own HEIs.

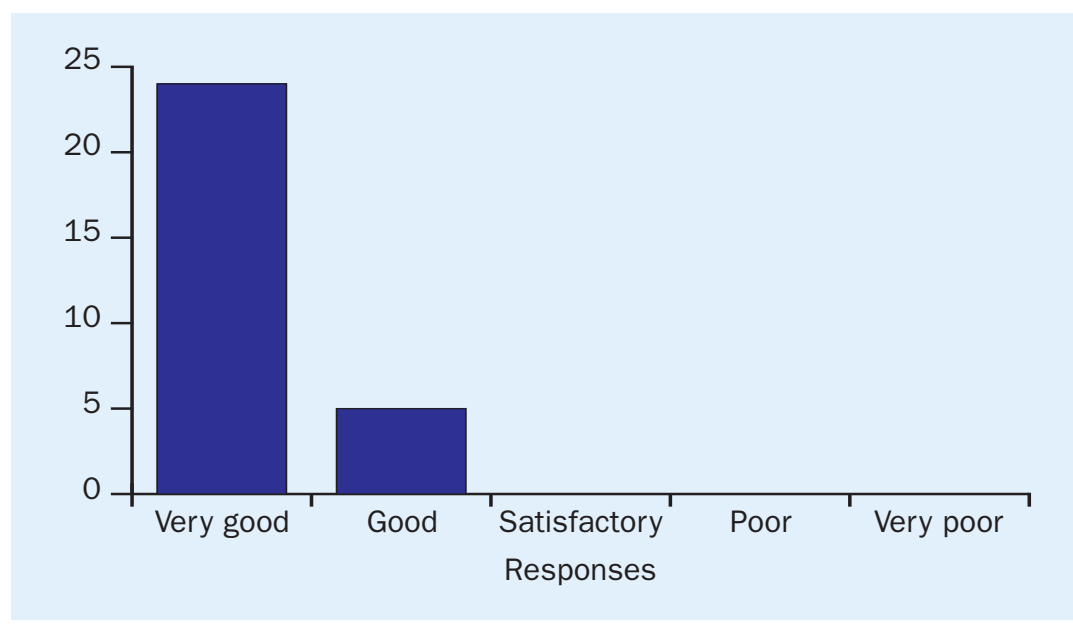

Figure 1. Good, clear aims and objectives

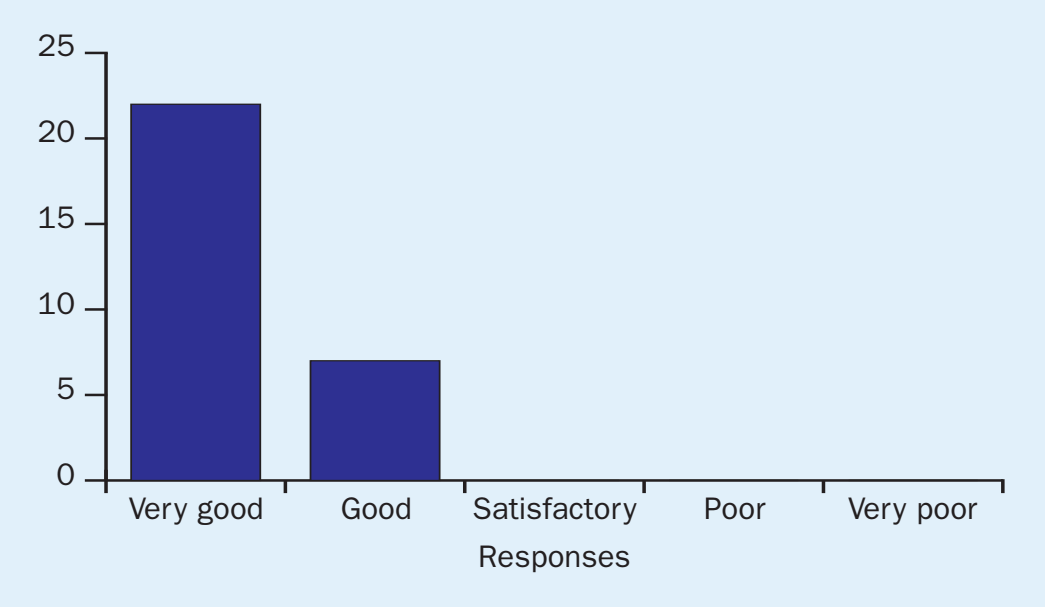

Figure 2. Achievement of aims and objectives

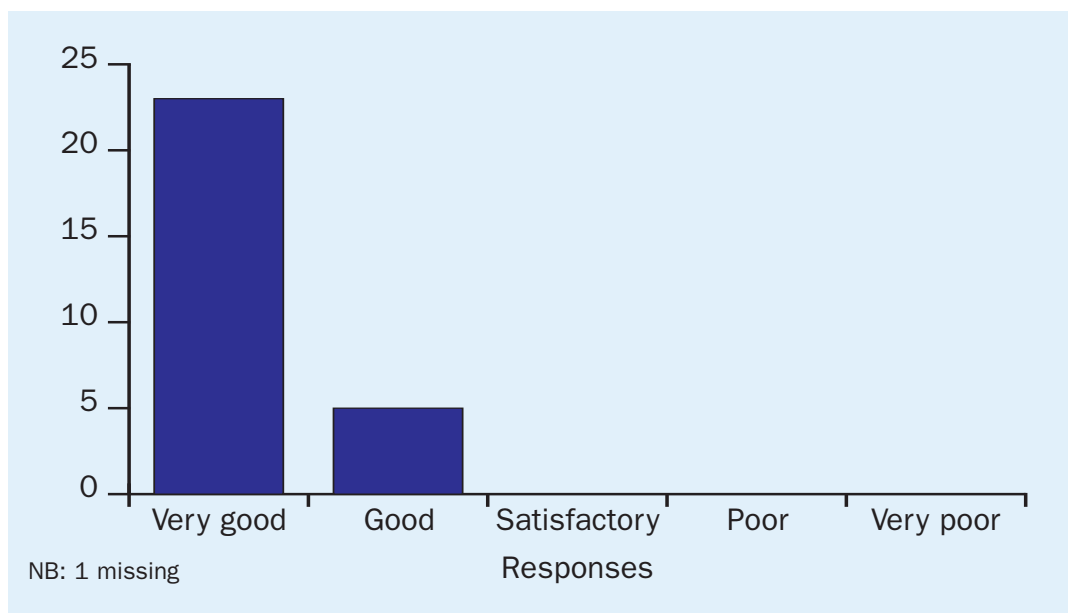

Figure 3. Ability to participate

\section{Workshops attended}

The participants had all attended at least one workshop and almost all had attended two. All of the workshops were represented, which included:

- Educational approaches

- Cultural and political perspectives of childbirth

- Research methodology and evidence-based practice 


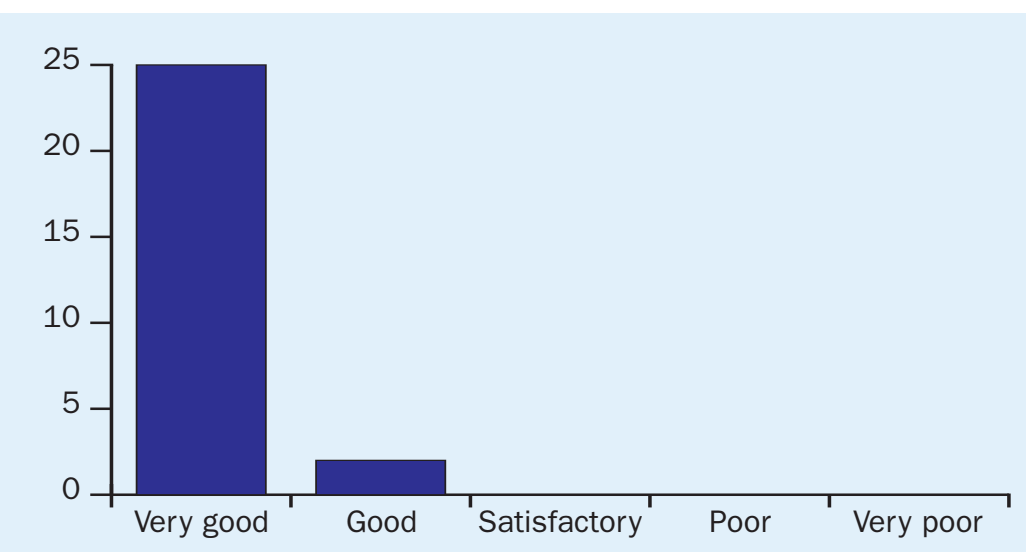

NB: 2 not applicable (not working in HEls) Responses

Figure 4. Relevance of workshop to own HEI

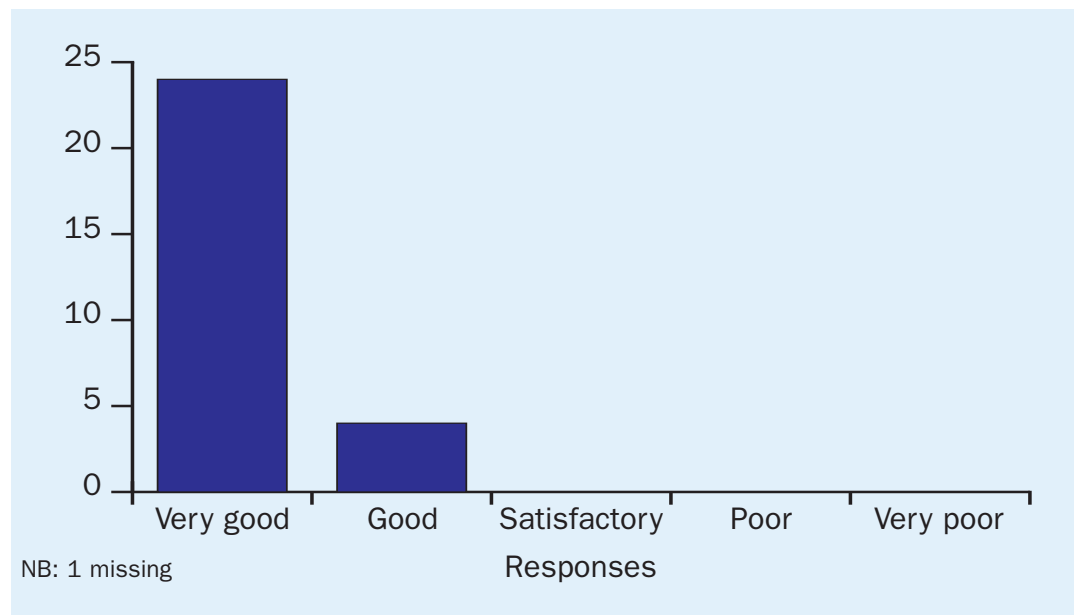

Figure 5. Ability to build personal capacity

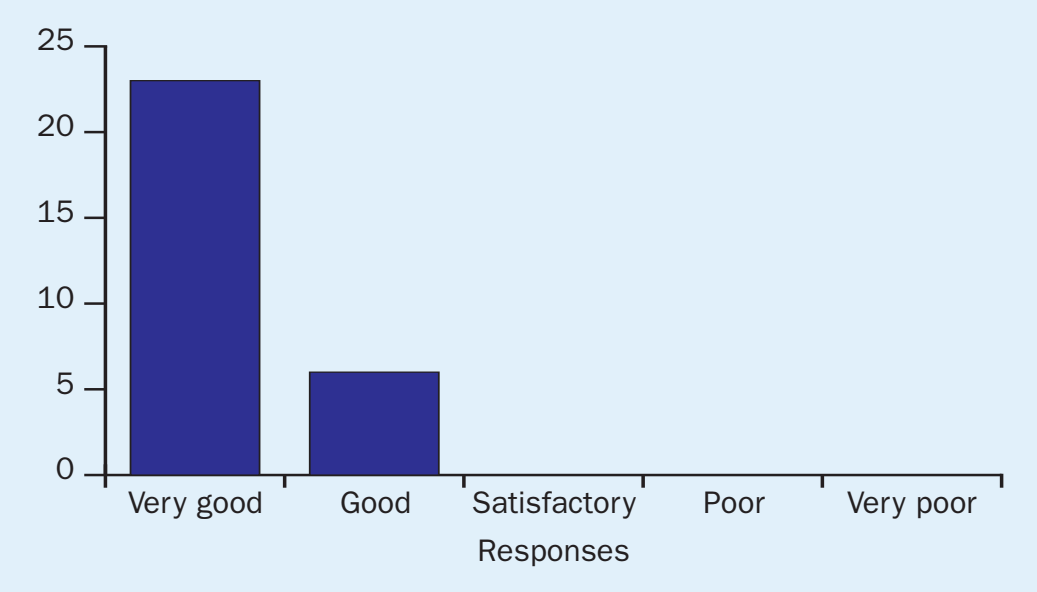

Figure 6. Quality of sessions

- Leadership and management;

- Advanced midwifery practice

- Women's health

- Community midwifery.

\section{Areas of exploration}

Aims and objectives of the workshops

All participants were happy with the aims and objectives set for the workshops (Figure 1). Comments included 'very clear', 'really clear'. Some participants described the aims as a 'challenge' or 'ambitious'. However, all participants felt that the aims and objectives were met (Figure 2) and some gave their reasons:

'The facilitators were very good, they made it easy to achieve the objectives.'

\section{'Everyone worked well towards a common goal.'}

\section{Ability to participate in workshops}

All those interviewed felt they had been able to participate in the workshop (Figure 3). There were positive comments about the facilitators making the workshops inclusive and non-judgmental:

'I was scared but there was no judgment about what I was saying, so I felt I could contribute without being scared.'

All felt that others in their groups also participated well and equitably:

$$
\begin{aligned}
& \text { 'I participated well and everybody else was } \\
& \text { participating.' }
\end{aligned}
$$

A group member, who was not a midwife, did not feel as able to contribute to discussions, but was able to provide support and contribution in relation to IT skills and giving feedback on presentations.

\section{Relevance to own HEI}

All participants felt the workshops were very relevant to their HEI (Figure 4). A participant commented on how this meeting helped her institution to identify deficiencies in their own programme and adapt accordingly:

'Very relevant because we are offering a masters course which did not encompass a lot of issues that were discussed at the workshops so it actually enriched our curriculum ... they were very helpful and beneficial.'

Some commented on the relevance to their country as a whole and relevance to the continent and world health:

'It was relevant because currently I think mother and child health is the key if you want to keep any population healthy and this will also contribute to the meeting of the millennium goals.'

\section{Building own personal capacity}

All participants felt they were able to build their personal capacity (Figure 5). In particular, meeting with others who were from slightly different roles and backgrounds was felt to be an enriching experience:

'Yes we regulate but no we don't teach, no we don't go to the clinical areas so we have people who are able to share experiences from what they are doing in their clinical 
areas and what they are doing in the classroom and that blend I think is very important. I think that blend really made us share ideas and learn so much.'

\section{Quality of sessions}

The quality of the sessions was described as 'good' or 'very good' (Figure 6). Participants acknowledged that the standard of attendees was very high as was the standard of facilitators. Many comments were made about the facilitators:

'It was very well laid out and what they did was very good the facilitators... They were assigned to their areas of expertise and when somebody is assigned to their area of expertise it became very easy to achieve all the objectives.'

'Well I think it all depends on the facilitators, you cannot really dismiss what a person is doing, some people are good at giving, some people have to go slow...'

\section{Room and facilities}

All commented about the size of the rooms made available by the hotel (Figure 8). The main room in particular was viewed as too small, however, the breakout rooms for the workshops were seen as adequate:

'The breakout rooms that we used for the workshops was fine, you didn't want them any bigger because you would have lost a lot. But obviously the rooms when we came together were not ideal, they were too small because they were all the same size rooms.'

Some commented on the fact that the hotel was busy:

'That place was actually full, I think they had a lot of activities going on and we were just pushed in a small room and I think it was not conducive.'

\section{How facilitators dealt with problems}

The main problem was seen to be the rooms and facilities available. However, interviewees acknowledged that the facilitators attempted to deal with this problem as far as possible:

'The only problem I could find in Uganda was about the room, but the facilitators apologised and a lot of things were done, tried, to make the situation much better.'

Two interviewees identified a problem with some individuals failing to share resources with the rest of the group:

'I note this comment that some people were not being very open and generous sharing some of the materials that they have brought. For me it didn't have any impact on the work we were doing, the knowledge of people and their expertise that is what really helped. Otherwise I don't think that had any impact and I don't think it was necessary to even address or to resolve that issue.'

One interviewee observed no problems.

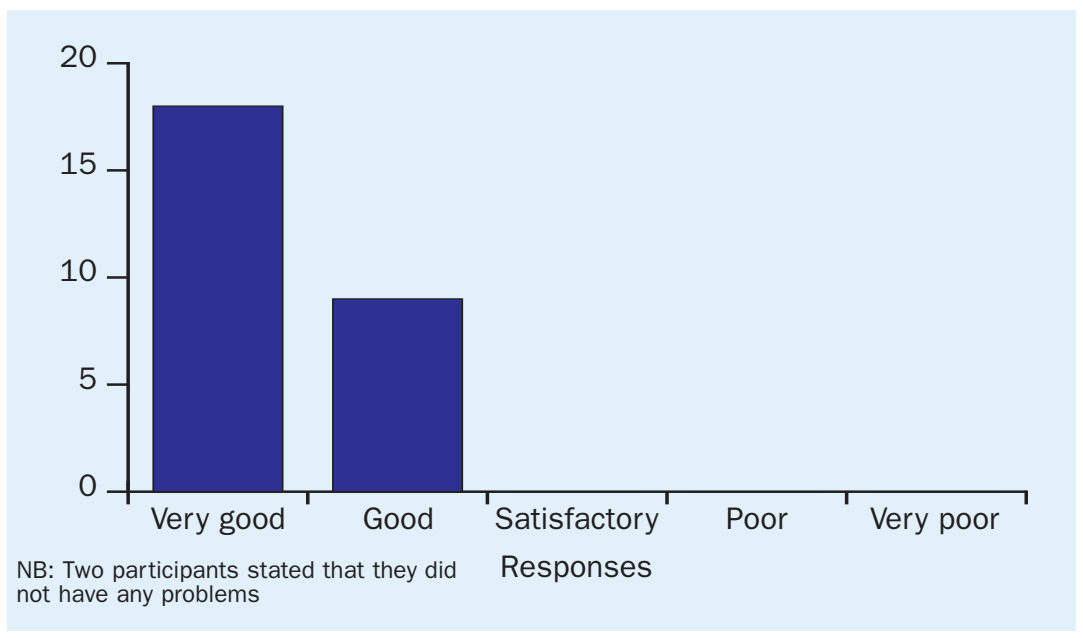

Figure 7. Help with problems during the workshop

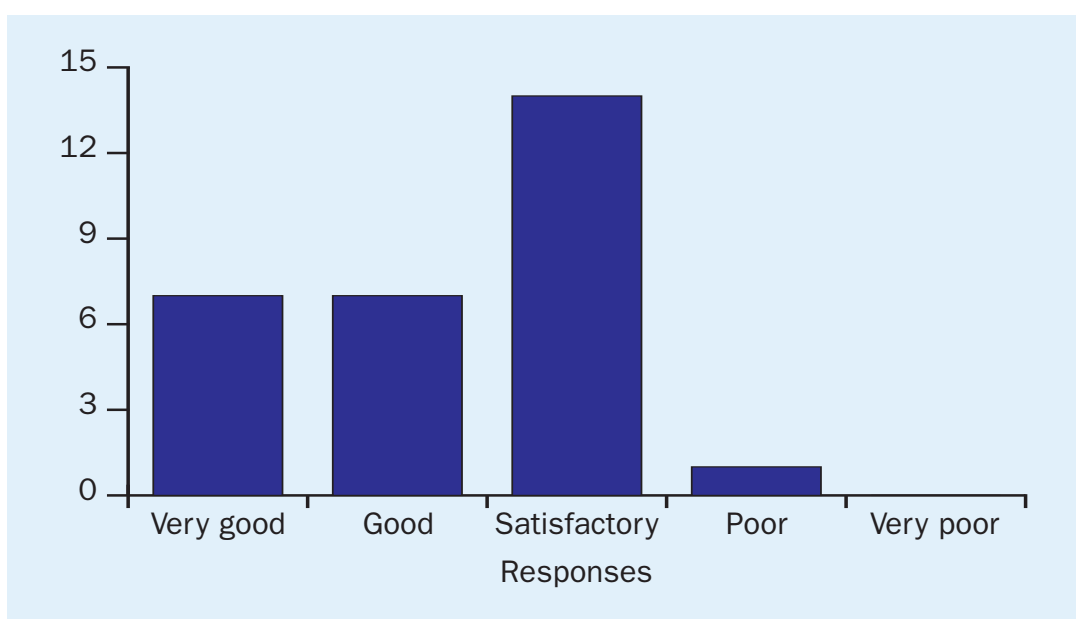

Figure 8. Satisfaction with room and facilities

Best aspects of the workshops

The participants commented overwhelmingly on the sharing of ideas and knowledge:

'The best thing again is the art of sharing, the art of respecting each other's opinion then nobody was told off "oh that's ridiculous" no we shared and gave expertise in the best way that we could, that we were able to share and come to consensus without voting.'

'.. actually being able to be involved in the development of the training itself and to come to the main group to get some input in what you have done, I think that was the best actually.'

'The best thing about the workshops I think it was just the sharing of the expertise and the information.'

'... seeing so many different people from so many different universities and organizations who could quite easily be in competition with each other all came with the same common goal and really, really worked hard, you could really see the progress that was being made so I think that was the best bit. There really was the sense of achievement at the end of the week.' 


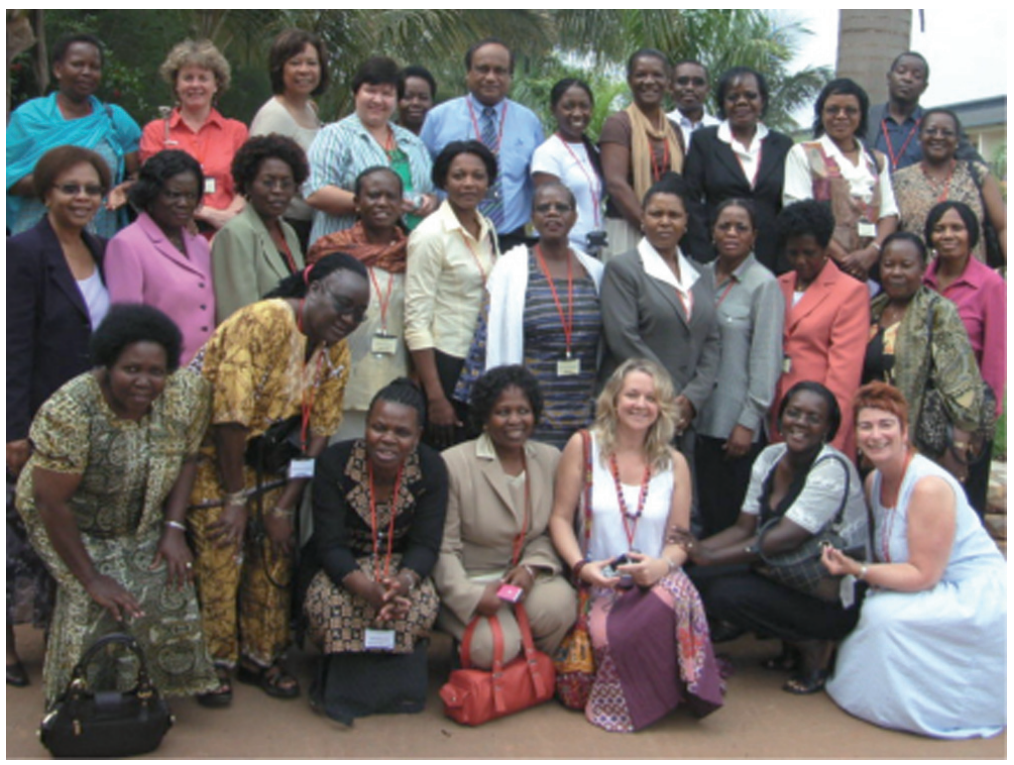

Facilitators and participants of the workshops

Changes to improve future workshops

All the interviewees indicated that having more resources available to them would be the main aspect they would change:

In hindsight I think if we had had some materials or access to some at the time we could have done even more in terms of what goes into the modules, but I think in a way you couldn't go with that already prepared otherwise what's the point of bringing everybody together to contribute, so I don't know that I would change anything.'

'We had to travel from various countries ... so sometimes we felt that maybe if we could have carried more materials or if we had access to a library but anyhow people managed and we had quite a few resource materials but also people had it in their own heads, as you know they were experts.,'

Some felt that allocating more time to the workshops would be an advantage:

'I would only change the time, maybe more sharing before because of resource constraints perhaps people may not have enough money to stay in a place for a long time but if we can share a lot before online.'

I think that I would have preferred if we had had more time, maybe eight days so that we could look at the content we had put in.'

One person felt that continuity of those involved in the process would be beneficial:

'It's good when there's continuity ... there are people that you are with [participants] so that you [can] continue from where you left [off] ... we had to go back to where we were with regard to bring them [new participants] to where people are. That I would change ... that continuity.'

All participants agreed strongly that they would participate in any similar workshops again.

\section{Sustainability}

All participants saw these workshops as the beginning of a process. They also believed that building educational capacity would have a wider impact:

'I think we really need to build capacity of the African woman. Africa is a unique problem, a unique problem that we as Africans can help to relieve to really minimize them. If your capacity is built I believe we will be empowered, we'll be talking from the point of knowledge and also with confidence so that we'll make a difference in our society. We have started with midwifery, there are lots of issues in community health, there are lots of issues in general nursing, so if we do midwifery I am saying that perhaps we finish this, let it not be the end, let us then go to the next level.'

\section{Summary}

Overall the participants were very positive about the workshop process and believed that all their aims and objectives were met. In particular, meeting with others was seen as a very positive and fruitful experience. Facilitators were praised for their skill and open, non-judgmental attitude.

The main problem was that of the rooms available for the plenary and workshops sessions at the hotel. It was acknowledged that the facilitators and organizers dealt with this as best they could and kept everyone informed. This was seen as positive. Suggestions made for the improvement of future workshops included more time and better access to resources (possibly online owing to difficulties in transporting such resources).

All participants interviewed believed the workshops to be of good quality and all felt they were able to build their personal capacity by attending them. The singular best aspect about the workshops was overwhelmingly perceived to be the sharing of knowledge and ideas with other participants from different institutions, countries and professional roles.

All participants interviewed would take part in a similar project again.

\section{Conclusion}

This project is unique in that it brought together a number of institutional representatives, from many different countries, with a shared goal of improving midwifery education. A key step in this process was the production of higher educational materials that midwives can access in their own country. It is envisaged that the project will help to build capacity among midwifery tutors who, in turn, will be able to train others to provide high-quality care. This project gave individual midwives a voice in determining what educational modules are available to them, therefore, ensuring local relevance and subsequent implementation of new knowledge and skills.

For those wishing to replicate this model of curriculum 


\section{Box 1. Core principles}

To be cross-national and transferable across borders

To be capable of increasing the number and capability of nurses and midwives in teaching and clinical skills

To be sustainable and cost effective

- Have clear collaborative roles of multiple partners

To be attractive, accessible and marketable to the target audience

To be evidence based, adaptable and flexible

Permit cultural diversity and politically acceptability

Meet prescribed standards (regional, national, international)

Include integrated monitoring and evaluation mechanisms demonstrating effectiveness and impact

- Have effective implementation strategies, taking into account available technologies and resources

To foster ownership among all stakeholders.

development, a number of factors need consideration. For such programmes to succeed, it is believed that a number of core principles must be achieved (Box 1). An attempt was made to address all these issues throughout the project.

Although the purpose of this project was to design and implement a Masters in Midwifery and Women's Health course, the lessons learnt from the process of carrying out this work are of equal value. One of the main challenges was 'cutting through the red tape'. Some individuals and organizations were nervous about contributing to a curriculum that has shared intellectual property. This was overcome through open communications and continual acknowledgement of all contributors. Further, as each institution has to validate the course individually, the actual content becomes specific to that university. Some participants were reluctant to share materials from their own institution, however, as the team built its relationship a level of trust emerged, which appeared to break down the competitiveness. Moreover, the emphasis on improving maternal and neonatal health was pivotal to working towards a common goal-and overpowered other concerns.

This project acts as an exemplar of international resource sharing. Every participant was able to draw on their own expertise to contribute to the group. In the ECSA region where resources are scarce, it is imperative that such pooling continues. One advantage of this process is that a consistent and high standard of course is developed that ensures equity for students, while maintaining content relevant to local context.

The sustainability of such programmes of work is perhaps the biggest challenge that is now faced. Progress is, however, promising. As well as offering the distance learning course in the UK, Malawi is now offering the course face to face and Kenya are beginning a validation process. Others (such as Zambia) have amended their existing masters courses to include aspects that previously were absent.

A.JM

\section{Funding}

The study was funded by the England-Africa Partnerships in Higher Education scheme, Department for Innovation, Universities and Skills, and the British Council

\section{Acknowledgments}

Dr Dintle KMogobe, University of Botswana, Botswana

Dr Joyce Musandu (deceased), School of Nursing Sciences,

Nairobi, Kenya

Mrs Elizabeth Oywer, Nursing Council of Kenya, Kenya

Mrs Dinah Jepkemoi Chelagat, Moi University, Kenya

Dr Address Malata, Kamuzu College of Nursing, Malawi

Mr Gurudeo Gobin, Principal Nurse Educator, Mauritius

Dr Scholastika N Iipinge, University of Namibia, Namibia

Ms Monica Servina, National Institute of Health and Social

Studies, Seychelles

Mrs Beryl Camille, National Institute of Health and Social

Studies, Seychelles

Mrs Antoinette Du Preez, North West University, South Africa

Prof Ntombifikile G Mtshali, University of KwaZulu-Natal,

South Africa

Dr Isabella S Ziyane, Faculty of Health Sciences, Swaziland

Mrs Scovia Nalugo Mbalinda, Makerere University, Uganda

Mrs F Rita Matte, Uganda Nurses and Midwives Council, Uganda

Mrs Speciosa Mbabali, Makerere University, Uganda

Ms Concepta Kwaleyela, University of Zambia, Zambia

Mrs Eleanor J Msidi, General Nursing Council of Zambia, Zambia

Ms Patritsia Matizha, University of Zimbabwe, Zimbabwe

Dr Christina Mudokwenyu-Rawdon, Zimbabwe

Mrs Nester $T$ Moyo, International Council of Midwives,

Netherlands

Dr Fiona Dykes, University of Central Lancashire, UK

Ms Lexa Kawala (deceased), ECSACON, Tanzania

Dr Melkizedeki S Kimaro, ECSA Health Community,

Tanzania

Ms Dotael E Kanza, Tanzania

Manongi RN, Marchant TC, Bygbjerg IC (2006) Improving motivation among primary health care workers in Tanzania: a health worker perspective. Hum Resour Health 4: 6

Mathauer I, Imhoff I (2006) Health worker motivation in Africa: the role of non-financial incentives and human resource management tools. Hum Resour Health 4: 24

United Nations General Assembly (2000) 55/2. United Nations millennium declaration. September 18. www.un.org/millennium/declaration/ares552e. pdf (accessed 1 October 2009)

United Nations General Assembly (2005) United Nations millennium declaration. September 14-16. www.un-ngls.org/orf/MDG/unaction.htm (accessed 7 October 2009)

World Health Organization (2006) The World Health Report 2006 Working together for Health. www.who.int/whr/2006/en (accessed 1 October 2009)

\section{Key Points}

Working across different health education institutions (HEIs), countries and continents is challenging but possible.

- Breaking down bureaucratic boundaries is essential for the advancement of midwifery education.

- Using participatory approaches to curriculum development can produce courses which are rich in context and offer students multiple cultural perspectives.

Working with HEls from different countries enables pooling of resources and expertise. 